\title{
Phonemic verbal fluency and severity of anxiety disorders in young children
}

\author{
Fluência verbal fonêmica e gravidade dos transtornos de ansiedade em \\ crianças pequenas
}

\author{
Rudineia Toazza, ${ }^{1,2}$ Giovanni Abrahão Salum, ${ }^{1,3}$ Rafaela Behs Jarros,,$^{1,3}$ Diogo DeSousa, ${ }^{1,4}$ \\ Jerusa Fumagalli de Salles, ${ }^{4,5}$ Gisele Gus Manfro ${ }^{1,2,3}$
}

\begin{abstract}
Introduction: Previous studies have implicated impaired verbal fluency as being associated with anxiety disorders in adolescents.

Objectives: To replicate and extend previously reported evidence by investigating whether performance in phonemic verbal fluency tasks is related to severity of anxiety symptoms in young children with anxiety disorders. We also aim to investigate whether putative associations are independent from co-occurring attention deficit hyperactivity disorder (ADHD) symptoms.

Methods: Sixty children (6-12 years old) with primary diagnoses of anxiety disorders participated in this study. Severity of symptoms was measured using clinician-based, parent-rated and self-rated validated scales. Verbal fluency was assessed using a simple task that measures the number of words evoked in 1-minute with the letter $F$, from which we quantified the number of isolated words, number of clusters (groups of similar words) and number of switches (transitions between clusters and/or between isolated words).

Results: There was a significant association between the number of clusters and anxiety scores. Further analysis revealed associations were independent from co-occurring ADHD symptoms. Conclusion: We replicate and extend previous findings showing that verbal fluency is consistently associated with severity in anxiety disorders in children. Further studies should explore the potential effect of cognitive training on symptoms of anxiety disorders.

Keywords: Anxiety disorders, executive function, verbal fluency, language.
\end{abstract}

\section{Resumo}

Introdução: Estudos prévios sugerem que déficits na fluência verbal estariam associados a transtornos de ansiedade em adolescentes.

Objetivo: Replicar e estender os resultados prévios investigando se o desempenho em uma tarefa de fluência verbal fonêmica está relacionado com a gravidade dos sintomas de ansiedade em crianças com transtorno de ansiedade. Pretendemos, também, investigar se essa associação é independente da coocorrência de sintomas de déficit de atenção e hiperatividade (TDAH).

Métodos: Participaram desse estudo 60 crianças (6-12 anos) com diagnóstico primário de transtorno de ansiedade. A gravidade dos sintomas foi medida utilizando escalas validadas baseadas para avaliação clínica, resposta dos pais ou responsáveis e resposta da criança. A fluência verbal foi avaliada utilizando uma tarefa simples que mede o número de palavras evocadas em 1 minuto com a letra $F$, a partir da qual foram quantificados o número de palavras isoladas, o número de clusters (agrupamentos de palavras semelhantes) e o número de switches (transições entre os agrupamentos e/ ou entre palavras isoladas).

Resultados: Encontramos uma associação significativa entre o número de clusters e os escores de ansiedade. Uma análise posterior revelou que essas associações foram independentes dos sintomas coocorrentes de TDAH.

Conclusões: Replicamos e estendemos os resultados anteriores mostrando que a fluência verbal está consistentemente associada com a gravidade dos transtornos de ansiedade em crianças. Novos estudos são incentivados com o objetivo de investigar potenciais efeitos de treinamentos cognitivos sobre os sintomas ansiosos em indivíduos com transtornos de ansiedade.

Descritores: Transtornos de ansiedade, funções executivas, fluência verbal, linguagem.

\footnotetext{
${ }_{1}$ Programa de Transtornos de Ansiedade na Infância e Adolescência (PROTAIA), Hospital de Clínicas de Porto Alegre (HCPA), Universidade Federal do Rio Grande do Sul (UFRGS), Porto Alegre, RS, Brazil. 2 Programa de Pós-Graduação em Neurociências, Instituto de Ciências Básicas da Saúde (ICBS), UFRGS, Porto Alegre, RS, Brazil. ${ }^{3}$ Programa de Pós-Graduação em Ciências Médicas: Psiquiatria, HCPA, UFRGS, Porto Alegre, RS, Brazil. ${ }^{4}$ Programa de Pós-Graduação em Psicologia, UFRGS, Porto Alegre, RS, Brazil. ${ }^{5}$ Núcleo de Estudos em Neuropsicologia Cognitiva (NEUROCOG), Departamento de Psicologia do Desenvolvimento e da Personalidade, Instituto de Psicologia, UFRGS, Porto Alegre, RS, Brazil.

Financial support: Fundo de Incentivo à Pesquisa e Eventos - Hospital de Clínicas de Porto Alegre (FIPE-HCPA). Rudineia Toazza receives doctoral scholarship from Coordenação de Aperfeiçoamento de Pessoal de Nível Superior (CAPES). Giovanni Abrahão Salum receives scholarship from Fundação de Amparo à Pesquisa do Estado do Rio Grande Do Sul (FAPERGS)/CAPES. Jerusa Fumagalli de Salles receives senior researcher scholarship from Conselho Nacional de Desenvolvimento Cientifico e Tecnológico (CNPq). Gisele Gus Manfro receives senior researcher scholarship from CNPq.

Submitted Feb 13 2016, accepted for publication Mar 08 2016. No conflicts of interest declared concerning the publication of this article.

Suggested citation: Toazza R, Salum GA, Jarros RB, DeSousa D, Salles JF, Manfro GG. Phonemic verbal fluency and severity of anxiety disorders in young children. Trends Psychiatry Psychother. 2016;38(2):100-104. http://dx.doi.org/10.1590/2237-6089-2016-0018
} 


\section{Introduction}

Anxiety disorders are common, cause significant impairment, and typically emerge during childhood and adolescence. ${ }^{1,2}$ Studying the disrupted information processing in cognitive functions associated with anxiety has the potential to further elucidate the pathophysiology of anxiety disorders. While many processes have been implicated in both adult and pediatric anxiety, ${ }^{1,3}$ deficits in specific aspects of executive functions have recently been receiving particular attention. ${ }^{4,5}$

A study by our group recently reported that children and adolescents from 10 to 17 years of age with anxiety disorders performed less well in a task of phonemic verbal fluency than a comparison group of typically developing children. This result seems to reflect specific deficits in executive function and, therefore, involvement of the prefrontal cortex in anxious children. ${ }^{5}$ However, this result has not been replicated in the literature so far and there are no studies specifically with young children. In addition, given the well-known associations between attention deficit hyperactivity disorder (ADHD) and executive functions, including lower performance in verbal fluency tasks, ${ }^{6,7}$ as well as the observation that ADHD symptoms frequently co-occur in children with anxiety disorders, 1 it is important to investigate whether associations between verbal fluency and severity of anxiety disorders might not be due to co-occurring ADHD symptoms.

Here we investigate whether performance in phonemic verbal fluency tests is related to the severity of anxiety symptoms in young children with anxiety disorders. We also investigate whether putative associations are independent from co-occurring ADHD symptoms. We hypothesized that verbal fluency deficits would be associated with anxiety severity in young children independently from ADHD symptoms.

\section{Method}

\section{Participants}

This study was approved by the Ethics Committee of the Hospital de Clínicas de Porto Alegre, Brazil (protocol no. 11-0249) and all parents signed an informed consent form. Sixty children (6-12 years) with a primary diagnosis of an anxiety disorder participated in this study. We included participants with the following characteristics: a) Primary diagnosis of generalized anxiety disorder (GAD), separation anxiety disorder (SeAD), or social anxiety disorder (SoAD) made according to standard diagnostic procedures described below. Exclusion criteria were: a) other psychiatric disorder judged by the clinician to cause more impairment or distress than GAD, SeAD, or SoAD; b) patients with previous psychiatric treatment including lifetime history of any type of psychotherapy or psychiatric medication; c) intellectual disability defined as a score below the 5th percentile on Raven's Progressive Matrices assessment.8,9 Participants were recruited by media advertisements and were prescreened with a brief telephone interview. Potentially eligible children and their parents were invited for a full diagnostic interview with a team of trained clinicians.

\section{Diagnosis}

All children underwent a comprehensive psychiatric diagnostic evaluation using the Schedule for Affective Disorders and Schizophrenia for School-Age ChildrenPresent and Lifetime Version (K-SADS-PL). ${ }^{10}$ The $\mathrm{K}-\mathrm{SADS}-\mathrm{PL}$ is a semi-structured interview used to diagnose childhood psychiatric disorders and is based on the Diagnostic and Statistical Manual of Mental Disorders, 4th edition, (DSM-IV) ${ }^{11}$ criteria. The K-SADS-PL has been adapted for Brazil and demonstrated good psychometric properties. ${ }^{12}$ Interviews were performed by doctoral or masters degree level clinicians and supervised by a senior clinician weekly.

\section{Measures of psychopathology severity}

The Pediatric Anxiety Rating Scale (PARS). This is a clinician-rated measure of anxiety. The scale rates anxiety severity, frequency, distress, avoidance, and interference using standardized methods. ${ }^{13}$ We used the scores on the 50 rated symptoms evaluated as present/ absent, giving a total score varying from 0 to 50 .

The Screen for Child Anxiety Related Emotional Disorders (SCARED). The SCARED ${ }^{14,15}$ scale is a 41-item measure of pediatric anxiety investigating symptoms of generalized anxiety ( 9 items), separation anxiety ( 8 items), SoAD (7 items), panic/somatic (13 items), and school phobia (4 items). Items are rated on a 3-point scale, and total scores range from 0 to 82 with higher scores reflecting higher anxiety levels. There is a self-report version and an equivalent parent-report version of the SCARED. The SCARED has been translated into Brazilian-Portuguese and this version demonstrated good psychometric properties. ${ }^{16,17}$ The SCARED total score (rather than subscale scores) was used as the dependent measure, as suggested in the literature. ${ }^{18}$

The Swanson, Nolan, and Pelham Questionnaire (SNAP-IV). The SNAP-IV has 18 items about ADHD symptoms and 8 additional items about oppositional- 
defiant symptoms. The questionnaire is a parent-rated 4-point scale, and total scores range from 0 to 78. The SNAP-IV has been successfully adapted into Brazilian Portuguese and functions well. ${ }^{19}$

\section{Verbal fluency}

Verbal fluency was assessed according to the number of words evoked in 1 minute with the letter $F$, a task which is part of the Brazilian Brief Neuropsychological Assessment Battery - NEUPSILIN (Child Version). ${ }^{20}$ The following variables were evaluated: 1 ) number of valid words (total words minus repetitions and rule violations); 2 ) number of clusters (groups of successively generated words that begin with the same first two letters [e.g., fire and financial], differed only in single vowel sounds [e.g., sit and set], produced rhymes [e.g., strip and ship], or were homonyms - starting and ending with the same sounds [e.g., see and sea]); 3) number of switches (transitions between clusters and/or between isolated words - which do not form clusters); and 4) isolated words (words that did not form clusters)..$^{21,22}$

This analysis provides, beyond the overall score, an evaluation of verbal fluency task, making it possible to investigate the cognitive processes underlying this neuropsychological function. ${ }^{21}$ Clusters provide information about categorization and switches evaluate cognitive flexibility. ${ }^{22}$

\section{Statistical analysis}

Initially we used multivariate general linear models with isolated words, clusters, and switches as dependent variables (which indicate the overall valid verbal fluency performance) and each anxiety symptom score (clinical, child and parent) separately as independent variables. Post-hoc univariate analyses were performed to identify which aspects of the verbal fluency task (isolated words, clusters or switches) were associated with anxiety symptom scales. Next, we repeated the models covarying for SNAP-IV scores in multiple linear regressions. A significance level of $5 \%$ was adopted.

\section{Results}

The mean age of the sample was 9.3 years (standard deviation $[S D]=1.6$ ) and $51.7 \%$ of participants were female. Mean scores for each symptomatic scale were as follows: PARS (mean $=20.1, \mathrm{SD}=7.06)$, SCARED-Parent $($ mean $=38.7, \mathrm{SD}=12.11)$, SCARED-Child $($ mean $=32.8$, $\mathrm{SD}=13.2$ ), and SNAP-IV (mean $=27.6, \mathrm{SD}=15.88)$. Main diagnoses were: SeAD $(n=48,80 \%)$, GAD ( $n=$
$44,73.3 \%)$, SoAD $(n=16,26.7 \%)$, panic $(n=6,10 \%)$ and agoraphobia $(n=12,20 \%)$. Comorbidities include: $\operatorname{ADHD}(n=13 ; 21.7 \%)$, major depression ( $n=8,13.3 \%)$, enuresis ( $n=5,8.3 \%)$ and oppositional defiant disorder (ODD) $(n=7,11.7 \%)$.

Descriptive statistics for the verbal fluency analysis were as follows: total number of words (mean $=7.2$, SD $=3.66$, minimum $[\mathrm{min}]=0$, maximum $[\max ]=21)$, valid words (mean $=6.8, \mathrm{SD}=3.6, \min =0, \max =21$ ), isolated words (mean $=2.9, \mathrm{SD}=2.14, \min =0, \max =$ 10 ), number of switches ( mean $=3.8, \mathrm{SD}=2.52, \min =0$, $\max =13$ ), number of clusters (mean $=1.72, \mathrm{SD}=1.15$, $\min =0, \max =4)$ and mean cluster size (mean $=2.2, \mathrm{SD}$ $=1.15, \min =0, \max =5$ ).

\section{Associations with anxiety scores}

In the multivariate model there were significant associations between overall verbal fluency performance and anxiety severity for clinician-rated measures, PARS (Pillai's Trace $=0.152, F_{3,55}=3.28, p=0.028$ ), parentrated measures, SCARED-P (Pillai's Trace $=0.141, F_{3,54}=$ $2.94, p=0.041$ ) and trend-level significance for child-rated measures, SCARED-C (Pillai's Trace $=0.108, F_{3,52}=2.09$, $p=0.112$ ). Post-hoc analysis for each of the measures revealed there were significant associations between the number of clusters and PARS $\left(F_{1,57}=6.73, p=0.012, \eta p^{2}\right.$ $=0.106)$, SCARED-P $\left(F_{1,56}=8.52, p=0.005, \eta p^{2}=0.132\right)$ and SCARED-C $\left(\mathrm{F}_{1,54}=6.10, \mathrm{p}=0.017, \eta \mathrm{p}^{2}=0.102\right)$; but no significant associations emerged for isolated words or number of switches (all $F>1.8$, all $\mathrm{p}>0.05$ ). A correlation matrix for all measures is shown in Table 1 . The table shows moderate to small effect sizes $(r \sim 0.3)$ for correlations between number of clusters and anxiety severity.

\section{Analysis of variance co-varying for ADHD symptoms}

Multiple regression models for number of clusters covarying for ADHD symptoms revealed that associations remained significant for PARS ( $\beta=-0.291, t=2.22, \mathrm{p}=$ $0.030)$, SCARED-P $(\beta=-0.324, t=2.43, p=0.018)$, and SCARED-C $(\beta=-0.290, t=2.15, \mathrm{p}=0.036)$. In contrast, no associations between ADHD symptoms and number of clusters emerged (all $p>0.05$ ); but ADHD symptoms were significantly associated with the number of isolated words and number of switches (Table 1 ).

\section{Discussion}

Our results showed that scores for severity of anxiety symptoms as assessed by clinicians, children and parents 
Table 1 - Univariate correlations between symptom scales and verbal fluency

\begin{tabular}{|c|c|c|c|c|c|c|c|}
\hline & \multicolumn{4}{|c|}{ Symptom scales } & \multicolumn{3}{|c|}{ Verbal fluency } \\
\hline & $\begin{array}{l}\text { SCARED } \\
\text { (parent) }\end{array}$ & $\begin{array}{l}\text { SCARED } \\
\text { (child) }\end{array}$ & $\begin{array}{c}\text { SNAP } \\
\text { (parent) }\end{array}$ & Total & $\begin{array}{l}\text { Isolated } \\
\text { words }\end{array}$ & Clusters & Switches \\
\hline \multicolumn{8}{|l|}{ Symptom scale } \\
\hline PARS (clinician) & $0.630 *$ & $0.436 *$ & 0.247 & -0.124 & 0.107 & $-0.325 t$ & -0.085 \\
\hline SCARED (parent) & - & $0.593 *$ & $0.345 \neq$ & -0.207 & -0.005 & $-0.363 \neq$ & -0.180 \\
\hline SCARED (child) & & - & $0.276+$ & -0.233 & -0.027 & $-0.319 t$ & -0.151 \\
\hline SNAP-IV (parent) & & & - & $-0.390 \neq$ & $-0.415 *$ & -0.227 & $-0.468 *$ \\
\hline \multicolumn{8}{|l|}{ Verbal fluency } \\
\hline Total valid $(n)$ & & & & - & $0.580 *$ & $0.741 *$ & $0.822 *$ \\
\hline Isolated words (n) & & & & & - & 0.050 & $0.878 *$ \\
\hline Clusters (n) & & & & & & - & $0.493 *$ \\
\hline Switches (n) & & & & & & & - \\
\hline
\end{tabular}

were negatively correlated with the number of clusters in a phonemic verbal fluency task and that these associations cannot be explained by co-occurring ADHD symptoms. These results replicate and extend our previous findings showing that verbal fluency is implicated in anxiety disorders even earlier in life.

In accordance with previous evidence ${ }^{5}$ and other studies with adults, ${ }^{23,24}$ anxiety was significantly associated with verbal fluency performance. Our current analysis revealed that for young children this association was explained by a lower number of clusters. This contrasts with our previous study that reported the presence of lower number of switches in anxious as compared to typically developing adolescents.

Clustering relates more strongly to phonemic memory, especially lexical storage of words; whereas switching relates more strongly to executive functions, search processes and cognitive flexibility. ${ }^{21,22}$ One possible explanation for anxiety to be associated with lower switching performance in adolescents and young adults and with poorer clustering in children is that it might be a result of an interaction between anxiety severity and developmental period. In our sample, switching significantly increases with age $(r=0.316, p=$ $0.019)$, but, in contrast, no associations between clustering and age were observed $(r=-0.006, p=0.970)$. Therefore, we hypothesize that whereas verbal fluency deficits are evident in clustering strategies in children (the strategy that prevails in children), anxiety is more strongly related to switching in adolescents (the strategy that prevails in adolescents and young adults). Another possibility is that whereas in young children deficits in verbal fluency might affect more general processes marked by clusters, ${ }^{25}$ in adolescents they might affect more specialized processes marked by switches. ${ }^{5,26}$ Lastly, the effects of time pressure, which might be specifically salient to anxiety disorder patients, might have different effects on verbal fluency components depending on developmental period.

Moreover, interestingly, we found that ADHD symptoms were independently related to switches, but not to clusters. Previous research has found ADHD in adults to be related to less switching, ${ }^{5,7}$ but other studies failed to find those association with switching in children. ${ }^{6}$ Nevertheless, these differential findings relating clusters to anxiety disorders and relating switching to ADHD provide an interesting avenue for further research aiming to differentiate anxiety from ADHD in young children.

We conclude that verbal fluency is consistently associated with the severity of anxiety symptoms, as replicated by our current findings. Our data reinforce the importance of verbal fluency as a marker of anxiety severity and recommend that further studies be conducted with the objective of investigating neurobiological measures and the therapeutic implications of our current findings. Interventions targeting mechanisms that support verbal fluency tasks (executive function, memory, language) at early ages may be the way to minimize future problems related to anxiety disorders.

\section{References}

1. Salum GA, DeSousa DA, Bosa VL, Schuch I, Goldani M, Isolan LR, et al. Internalizing disorders and quality of life in adolescence: evidence for independent associations. Rev Bras Psiquiatr. 2014;36:305-12.

2. Merikangas KR, He JP, Burstein M, Swanson SA, Avenevoli S, Cui L, et al. Lifetime prevalence of mental disorders in U.S. adolescents: results from the National Comorbidity Survey Replication--Adolescent Supplement (NCS-A). J Am Acad Child Adolesc Psychiatry. 2010;49:980-9.

3. Pine DS. Research review: a neuroscience framework for pediatric anxiety disorders. J Child Psychol Psychiatry. 2007;48:631-48.

4. Mogg K, Salum GA, Bradley BP, Gadelha A, Pan P, Alvarenga $P$, et al. Attention network functioning in children with anxiety disorders, attention-deficit/hyperactivity disorder and non-clinical anxiety. Psychol Med. 2015;45:2633-46. 
5. Toazza R, Salum GA, Flores SM, Jarros RB, Pine DS, de Salles JF, et al. Phonemic verbal fluency is associated with pediatric anxiety disorders: evidence from a community study. J Child Adolesc Psychopharmacol. 2014;24:149-57.

6. Takács Á, Kóbor A, Tárnok Z, Csépe V. Verbal fluency in children with ADHD: strategy using and temporal properties. Child Neuropsychol. 2014;20:415-29.

7. Tucha O, Mecklinger L, Laufkötter R, Kaunzinger I, Paul GM, Klein $\mathrm{HE}$, et al. Clustering and switching on verbal and figural fluency functions in adults with attention deficit hyperactivity disorder. Cogn Neuropsychiatry. 2005;10:231-48.

8. Raven JC, Raven J, Court JH. Matrizes progressivas coloridas de Raven. Manual. São Paulo: Casa do Psicólogo; 1988.

9. Angelini $A L$, Alves IC, Custódio EM, Duarte WF, Duarte JL. Matrizes progressivas coloridas de Raven: escala especial. São Paulo: Centro Editor de Testes de Pesquisas em Psicologia; 1999.

10. Kaufman J, Birmaher B, Brent D, Rao U, Flynn C, Moreci P, et al. Schedule for Affective Disorders and Schizophrenia for SchoolAge Children-Present and Lifetime Version (K-SADS-PL): initial reliability and validity data. J Am Acad Child Adolesc Psychiatry. 1997;36:980-8.

11. American Psychiatric Association. Diagnostic and Statistical Manual of Mental Disorders, Third Edition (DSM-III). Washington: American Psychiatric Publishing; 1980.

12. Brasil HHA. Development of the Brazilian version of K-SADS-PL (Schedule for Affective Disorders and Schizophrenia for School Aged Children Present and Lifetime Version) and study of psychometric properties [dissertation]. São Paulo: Universidade Federal de São Paulo; 2003.

13. The Pediatric Anxiety Rating Scale (PARS): development and psychometric properties. J Am Acad Child Adolesc Psychiatry. 2002;41:1061-9.

14. Birmaher B, Khetarpal S, Brent D, Cully M, Balach L, Kaufman J, et al. The Screen for Child Anxiety Related Emotional Disorders (SCARED): scale construction and psychometric characteristics. J Am Acad Child Adolesc Psychiatry. 1997;36:545-53.

15. Birmaher B, Brent DA, Chiappetta L, Bridge J, Monga S, Baugher M. Psychometric properties of the Screen for Child Anxiety Related Emotional Disorders (SCARED): a replication study. J Am Acad Child Adolesc Psychiatry. 1999;38:1230-6.

16. Desousa DA, Salum GA, Isolan LR, Manfro GG. Sensitivity and specificity of the Screen for Child Anxiety Related Emotional Disorders (SCARED): a community-based study. Child Psychiatry Hum Dev. 2013;44:391-9.

17. Isolan L, Salum GA, Osowski AT, Amaro E, Manfro GG. Psychometric properties of the Screen for Child Anxiety Related Emotional Disorders (SCARED) in Brazilian children and adolescents. J Anxiety Disord. 2011;25:741-8.
18. DeSousa DA, Zibetti MR, Trentini CM, Koller SH, Manfro GG, Salum GA. Screen for child anxiety related emotional disorders: are subscale scores reliable? A bifactor model analysis. J Anxiety Disord. 2014;28:966-70.

19. Mattos $P$, Serra-Pinheiro MA, Rohde LA, Pinto D. Apresentação de uma versão em português para uso no Brasil do instrumento MTA-SNAP-IV de avaliação de sintomas de transtorno do déficit de atenção/hiperatividade e sintomas de transtorno desafiador e de oposição. Rev Psiquiatr Rio Gd Sul. 2006;28:290-7.

20. Salles JF de, Fonseca RP, Cruz-Rodrigues C, Mello CB, Barbosa T, Miranda MC. Desenvolvimento do Instrumento de Avaliação Neuropsicológica Breve Infantil NEUPSILIN-INF. Psico-USF. 2011;16:297-305

21. Becker N, Salles JF. Methodological criteria for scoring clustering and switching in verbal fluency tasks. Psico-USF. Forthcoming 2016.

22. Troyer AK, Moscovitch M, Winocur G. Clustering and switching as two components of verbal fluency: evidence from younger and older healthy adults. Neuropsychology. 1997;11:138-46.

23. Nishimura $Y$, Tanii $H$, Hara N, Inoue $K$, Kaiya $H$, Nishida $A$, et al. Relationship between the prefrontal function during a cognitive task and the severity of the symptoms in patients with panic disorder: a multi-channel NIRS study. Psychiatry Res. 2009; $172: 168-72$

24. Nelson BD, Sarapas C, Robison-Andrew EJ, Altman SE, Campbell $\mathrm{ML}$, Shankman SA. Frontal brain asymmetry in depression with comorbid anxiety: a neuropsychological investigation. J Abnorm Psychol. 2012;121:579-91.

25. Resch C, Martens R, Hurks P. Analysis of young children's abilities to cluster and switch during a verbal fluency task. Clin Neuropsychol. 2014;28:1295-310.

26. Lanting S, Haugrud N, Crossley M. The effect of age and sex on clustering and switching during speeded verbal fluency tasks. J Int Neuropsychol Soc. 2009;15:196-204.

\section{Correspondence:}

Rudineia Toazza

Hospital de Clínicas de Porto Alegre

Rua Ramiro Barcelos, 2350, sala 2202

90035-003 - Porto Alegre, RS - Brazil

Tel./Fax: +55 (51) 3359.8983

E-mail: rudineiatoazza@yahoo.com.br 